\title{
Ageism and loneliness in the subjective perceptions of elderly people from nursing homes and households
}

\author{
ANDREI SHPAKOU ${ }^{1, A-G}$, LUDMILA KLIMATCKAIA2, A, B, D-G , TATIANA FURIAEVA 2, A, E, F, \\ ORCID ID: 0000-0003-4340-5211 ORCID ID: 0000-0001-8926-2901 \\ SIARHEI PIATROU ${ }^{1, A, ~ C, ~ D, ~ F, ~ O L G A ~ Z A I T S E V A ~} 3$, A, B, D, F \\ ORCID ID: 0000-0003-2333-5359 ORCID ID: 0000-0001-7199-2308 \\ ORCID ID: 0000-0002-7709-1102 \\ ${ }^{1}$ Department of Theory of Physical Culture and Sports Medicine, Yanka Kupala State University of Grodno, \\ Grodno, Belarus \\ ${ }^{2}$ Department of Social Pedagogy and Social Work, Krasnoyarsk State Pedagogical University named after \\ V.P. Astafiev, Krasnoyarsk, Russia \\ ${ }^{3}$ Department of Clinical Pathophysiology, Scientific Research Institute of the North Medical Problems, Siberian \\ Branch of the Russian Academy of Sciences, Krasnoyarsk, Russia
}

A - Study Design, B - Data Collection, C - Statistical Analysis, D - Data Interpretation, E - Manuscript Preparation, F - Literature Search, G - Funds Collection

Summary Background. Ageism and loneliness in old age are largely dependent on the social causes that force elderly people to seek long-term care in nursing homes.

Objectives. To study and assess the phenomenon of ageism and the experience of loneliness based on the perceptions of elderly people from nursing homes and households.

Material and methods. Elderly people (42 women and 20 men) aged $65+(76,0 \pm 5,24)$ years were examined. Group I included 29 people living in a nursing home, while group II included 33 people living in households. The levels of ageism were evaluated according to the Fraboni scale, while the experience of loneliness was evaluated based on the UCLA method.

Results. We found that the level of ageism was classified as neutral in $80 \%$ of the respondents and did not differ significantly in the groups. Only the classification "alienation, avoidance" in the Fraboni scale was expressed more in group II ( $p<0.05)$. Group I informants were twice as likely to experience a high level of loneliness $(p<0.05)$. For respondents from nursing home, a high level of loneliness was facilitated by the phenomenon of the closed structure of institutions of social services. For those living in households, the experience of loneliness was more typical in connection with the manifestations of ageism in the form of gerontostereotypization, discrimination and especially alienation-avoidance.

Conclusions. Manifestations of ageism and loneliness were identified among the elderly in both groups and each have their own characteristics. The high level of loneliness and ageism among the elderly should be considered as factors contributing to the emergence of psycho-emotional disorders.

Key words: nursing homes, loneliness, ageism, marital status, aged.

Shpakou A, Klimatckaia L, Furiaeva T, Piatrou S, Zaitseva O. Ageism and loneliness in the subjective perceptions of elderly people from nursing homes and households. Fam Med Prim Care Rev 2021; 23(4): 475-480, doi: https://doi.org/10.5114/fmpcr.2021.110366.

\section{Background}

The aging of the population poses serious challenges to public health and the social policy of the state [1]. Old age is just beginning to be understood as a period that conceals great reserves and opportunities $[2,3]$. Representatives of the $65+$ age group are a special social group and require attention not only from the family but also from society as a whole [4]. Thanks to the progress of medicine in the prevention, diagnosis and treatment of diseases, including diseases associated with age, most people over 65 years continue to be socially active. Unfortunately, some older adults reduce their previous activities for various reasons, which often leads to the loss of social contacts and loneliness [5]. Most people would like to live in their own home, cared for by their family, not strangers, and not to become a burden to their relatives. Unfortunately, this is not always possible due to difficult life situations (loss of house or restrictions in self-care) or the refusal of children to take care of their parents. An increase in life expectancy and an increase in the number of older adults is likely to increase the demand for long-term social services [6]. The living conditions of the elderly in specialized institutions do not always meet the modern criteria of comfort and preservation of the dignity of old age [7].

The relevance and significance of the research topic specifies the growing number of older adults who apply to social service institutions. It is known that older adults who find themselves in new conditions of living in an nursing home are forced to abandon their usual way of life, reduce the level of social claims, part with their hopes and plans, move to a different social status, revise the existing system of values and change the usual style of interaction between people. Limited external access to clients of nursing homes contributes to higher levels of loneliness and ageism among the elderly [8].

Robert Butler defined ageism as the social stereotyping and discrimination of people based on age [9]. Most often, gerontological ageism is associated with a biased attitude towards the elderly, as a type of social discrimination, including negative, dismissive or degrading attitudes, together with practices implemented on the basis of negative age stereotyping and avoidance $[10,11]$. Deeply rooted social attitudes towards older adults is 
a serious obstacle to the full realization of the need for communication, which is subjectively assessed as loneliness $[12,13]$.

Loneliness is usually understood as a negative socio-psychological experience that occurs as a result of inadequate satisfaction of the social needs of the individual, the consequence of which is a feeling of uselessness, abandonment and loss of emotional connection with others [14]. The reality of aging is connected to many causes of loneliness [13]. Thus, in longitudinal studies, the relationship between the experience of loneliness and subjectively perceived disadvantage in society is revealed [10]. Often, loneliness is characterized by the presence of individual experiences of varying intensity, which have a predominantly negative emotional coloring [15].

The hypothesis of the study is that the level of gerontological ageism and the experience of loneliness in a sample of elderly adults living in a nursing home and their peers living in households have their own characteristics in subjective perception and may be related to the phenomenon of privacy in Russian social service institutions (nursing homes).

\section{Objectives}

To study the phenomenon of ageism and the experience of loneliness, to assess the comparative aspect of subjective perception level for these phenomena among elderly people from nursing homes and households.

\section{Material and methods}

\section{Study design}

The study sample is represented by two groups of elderly people with age-related diseases without disability within the $65+$ age group. The sample included a total of 62 people (42 women and 20 men). Group I included 29 elderly adults who lived in public nursing home in Krasnoyarsk (at least 360 days). The living conditions were satisfactory, apartment-by-apartment accommodation of the hostel type. The standard of this type of social institutions provides for the services necessary for the elderly (with usual source of care). Group II included 33 elderly adults living in households. Inclusion criteria: men and women aged $65+$ with age-related illnesses in remission, permanently living in a nursing home (at least 360 days) or in a household. Exclusion criteria: acute and chronic infections; diseases of the central nervous system: metabolic, oncological, etc., as well as TBI, epilepsy, psychosis; somatic diseases (III degree hypertension, ischemic heart disease, bronchial asthma, diabetes, etc.); taking sedatives, antidepressants, alcoholism and drug addiction. People aged $65+$ were enrolled in the study after obtaining their written consent.

\section{Data collection}

The research was conducted in 2020. Before starting the follow-up, all the participants were informed about its goals and methodology. The respondents were also confident in complete anonymity and voluntary participation in the survey.

\section{Measures}

\section{The Fraboni Ageism Scale}

This project used the generally accepted method of assessing ageism based on the Fraboni scale [16] in its Russian-language interpretation [17]. The value of Cronbach's alpha for all factors exceeded 0.80 (varying across scales from 0.75 to 0.86 ). Respondents were asked to rate 25 standard statements about elderly people. For the answers, a 4-point psychometric Likert scale was used. The total score was based on the answers to the questions of three classical scales: "Age stereotypes and prejudices", "Discrimination and negative emotional attitudes" and
"Alienation, avoidance". A higher total score indicated a greater age bias towards oneself and peers.

\section{UCLA Loneliness Scale}

To diagnose the subjective perception of loneliness, we used the generally accepted scale of UCLA (University of California Los Angeles) by D. Russell and M. Ferguson, which is used to study a mainly one-dimensional approach to determining the perception of loneliness in a predominantly negative light [18]. Cronbach's $\alpha$ coefficient of the questionnaire is 0.79 . The scale uses 11 negatively ("lonely") and 9 positively ("not alone") rated statements. The total indicator allows you to diagnose a construct with the following factors: lack of unity with others; lack of interpersonal contacts with relatives; alienation, isolation; dissatisfaction with the quality of relationships with others [19]. All this can be interpreted as a state of forced isolation and as a desire or need for solitude.

\section{Ethical considerations}

All procedures performed in the studies involving human participants were in accordance with the ethical standards of the institutional research committee and with the 1964 Helsinki Declaration and its later amendments or comparable ethical standards. The study did not infringe upon human rights and did not endanger the respondents. It also met the requirements of biomedical ethics: reviewed and approved in accordance with the GCP rules by the Scientific Research Institute of the North Medical Problems, Siberian Branch of the Russian Academy of Sciences, Krasnoyarsk, Russia (06.06. 2020, N6).

\section{Statistical methods}

The statistical software package Statistica 13 PL (StatSoft, USA) was used for classical statistical processing and searching for significant dependencies of indicators in the studied groups. The correspondence of the obtained values to the law of normal distribution of the variation series was preliminarily evaluated using the Shapiro-Wilk W-statistical test. Since the final quantitative indicators on all scales and the total levels of ageism and loneliness experience had a different distribution from the norm, nonparametric evaluation criteria were used for processing and interpreting the results. Descriptive statistics included the median, the minimum and maximum values and the interquartile range-IQR (difference value of 25 top 75 lower quartiles). In addition, the following generally accepted indicators were used: the arithmetic mean (Mean), together with the standard deviation (SD). The formula for the Wilson score interval was applied when calculating $95 \% \mathrm{Cl}$ for level of loneliness. To assess the reliability of the differences between the two groups of respondents, the Mann-Whitney U-test was used. In all analyses, a $p$-value less than 0.05 was considered statistically significant.

In addition, to determine possible natural groupings and the main dependencies between the indicators of the primary scales of the questionnaires, an exploratory factor analysis using the principal component analysis (Exploratory Factor Analysis - EFA) [20] was conducted. The calculations were performed in the statistical data analysis environment $\mathrm{R}$ ( $\mathrm{r}$-project.org, version 4.0.3). The analyzed data set was an array of indicators of the primary scales of both questionnaires. The indicator of an informant belonging to the group of elderly people in inpatient social service institutions and those living in a household was not included in the analysis but was used only for marking respondents correlated according to the results of the exploratory factor analysis.

\section{Results}

There were no differences in age $(76.6 \pm 6.18$ vs $75.5 \pm 4.66$ years) and gender ( $34.5 \%$ of men in group I and $30.3 \%$ in group II). Descriptive results of gerontological ageism and loneliness by group are presented in Table 1. 
Of the three Fraboni scales, only the "alienation, avoidance" scale showed statistically significant differences between the groups, with a more pronounced indicator in people living in households $(p<0.05)$. There were no significant differences in the total ageism index. The experience of loneliness is significantly more pronounced in group I informants compared to group II $(p<0.05)$.

According to the data obtained using the UCLA scale, respondents in each of the groups were identified who showed different levels of loneliness experience in the range from 20 to 80 points. A low level (less than 40 points) was not observed among the respondents of both groups. An average level (40-60 points) was observed in 48 people (77.4\%). A high level (more than 60 points) was found in 14 respondents (22.6\%). The ranges of the level of loneliness experience in the respondents in the study groups are presented in Table 2.

Table 3 shows the leading statements on the ageism and loneliness scales where there were statistically significant differences between groups.

\begin{tabular}{|c|c|c|c|c|c|c|}
\hline & Group & Median & $\begin{array}{l}\text { Minimum- } \\
\text {-maximum }\end{array}$ & IQR & Mean (SD) & $\begin{array}{l}\text { Mann-Whitney } \\
\text { criterion, Z }\end{array}$ \\
\hline \multirow{3}{*}{$\begin{array}{l}\text { Age-related stereotypes and } \\
\text { prejudices (Fraboni scale) }\end{array}$} & 1 & 25.0 & $15-30$ & $22-27$ & $24.1(4.03)$ & \multirow[t]{3}{*}{$0.46, p>0.05$} \\
\hline & II & 24.0 & $18-29$ & $22-25$ & $23.9(2.84)$ & \\
\hline & both groups & 24.0 & $15-30$ & $22-27$ & $24.0(3.42)$ & \\
\hline \multirow{3}{*}{$\begin{array}{l}\text { Discrimination and negative } \\
\text { emotional attitudes (Fraboni } \\
\text { scale) }\end{array}$} & 1 & 16.0 & $11-21$ & $15-18$ & $16.1(2.41)$ & \multirow[t]{3}{*}{$-0.18, p>0.05$} \\
\hline & II & 16.0 & $12-21$ & $15-18$ & $16.1(2.19)$ & \\
\hline & both groups & 16.0 & $11-21$ & $15-18$ & $16.1(2.28)$ & \\
\hline \multirow{3}{*}{$\begin{array}{l}\text { Alienation, avoidance (Fraboni } \\
\text { scale) }\end{array}$} & 1 & 17.0 & $10-29$ & $16-19$ & $17.3(3.38)$ & \multirow[t]{3}{*}{$-2.07, p<0.05$} \\
\hline & II & 18.0 & $15-24$ & $17-20$ & $18.5(2.11)$ & \\
\hline & both groups & 18.0 & $10-29$ & $16-19$ & $17.9(2.82)$ & \\
\hline \multirow{3}{*}{$\begin{array}{l}\text { Total levels of ageism (Fraboni } \\
\text { scale) }\end{array}$} & 1 & 58.0 & $43-80$ & $51-62$ & $57.5(7.87)$ & \multirow[t]{3}{*}{$-0.72, p>0.05$} \\
\hline & II & 57.0 & $48-70$ & $55-62$ & $58.5(5.41)$ & \\
\hline & both groups & 57.0 & $43-80$ & $53-62$ & $58.1(6.74)$ & \\
\hline \multirow{3}{*}{$\begin{array}{l}\text { Summary criterion for experienc- } \\
\text { ing loneliness (UCLA scale) }\end{array}$} & 1 & 57.0 & $50-64$ & $54-60$ & $57.1(3.90)$ & \multirow[t]{3}{*}{$2.16, p<0.05$} \\
\hline & II & 54.0 & $43-62$ & $52-58$ & 54.5 (4.49) & \\
\hline & both groups & 56.0 & $43-64$ & $52-59$ & $55.7(4.40)$ & \\
\hline
\end{tabular}

\begin{tabular}{|c|c|c|c|c|}
\hline \multirow[t]{2}{*}{ Groups } & \multicolumn{3}{|c|}{ Loneliness scores } & \multirow[t]{2}{*}{ Pearson's criterion $\chi 2$} \\
\hline & $\begin{array}{l}\text { Low } \\
\text { (less } 40 \text { points) }\end{array}$ & $\begin{array}{l}\text { Middle } \\
\text { (40-60 points) }\end{array}$ & $\begin{array}{l}\text { High } \\
\text { (more } 60 \text { points) }\end{array}$ & \\
\hline I & 0 & $\begin{array}{l}20(69.0 \%) \\
52.1-85.8\end{array}$ & $\begin{array}{l}9(31.0 \%) \\
14.2-47.9\end{array}$ & \multirow[t]{2}{*}{$2.23, p>0,05$} \\
\hline II & 0 & $\begin{array}{l}28(84.8 \%) \\
72.6-97.1\end{array}$ & $\begin{array}{l}5(15.2 \%) \\
2.9-27.4\end{array}$ & \\
\hline Both groups & 0 & $\begin{array}{l}48(77.4) \\
67.0-87.8\end{array}$ & $\begin{array}{l}14(22.6) \\
12.2-33.0\end{array}$ & \\
\hline
\end{tabular}

\begin{tabular}{|c|c|c|c|c|c|}
\hline \multirow[t]{2}{*}{$\begin{array}{l}\text { Criterion } \\
\text { number }\end{array}$} & \multirow[t]{2}{*}{ Approvals } & \multicolumn{2}{|c|}{$\begin{array}{l}\text { Group (Median; min-max; } \\
\text { Mean (SD)) }\end{array}$} & \multicolumn{2}{|c|}{ Mann-Whitney U-test } \\
\hline & & $\mid$ & II & $z$ & $p$ \\
\hline \multicolumn{6}{|c|}{$\begin{array}{l}\text { Fraboni Scale } \\
\text { Age-related stereotypes and prejudices }\end{array}$} \\
\hline №1 & Teenage suicide is more tragic than suicide among the elderly & $\begin{array}{l}3.0 ; 1-4 ; 2.62 \\
(0.82)\end{array}$ & $\begin{array}{l}3.0 ; 1-4 ; 3.12 \\
(0.86)\end{array}$ & -2.17 & 0.03 \\
\hline № 3 & $\begin{array}{l}\text { Many elderly people are stingy and hoard their money and pos- } \\
\text { sessions }\end{array}$ & $\begin{array}{l}2.0 ; 1-4 ; 2.41 \\
(0.73)\end{array}$ & $\begin{array}{l}1.0 ; 1-4 ; 1.61 \\
(0.79)\end{array}$ & 3.69 & 0.001 \\
\hline № 7 & $\begin{array}{l}\text { I don't like it when elderly people try to make conversation with } \\
\text { me }\end{array}$ & $\begin{array}{l}1.0 ; 1-4 ; 1.69 \\
(0.89)\end{array}$ & $\begin{array}{l}2.0 ; 1-4 ; 2.21 \\
(0.74) \\
\end{array}$ & -2.63 & 0.01 \\
\hline № 24 & Elderly people complain more than other people do & $\begin{array}{l}3.0 ; 1-4 ; 2.69 \\
(0.93)\end{array}$ & $\begin{array}{l}3.0 ; 2-4 ; 3.45 \\
(0.66)\end{array}$ & -3.16 & 0.001 \\
\hline №25 & Elderly people do not need much money to meet their needs & $\begin{array}{l}3.0 ; 1-4 ; 2.62 \\
(1.05)\end{array}$ & $\begin{array}{l}2.0 ; 1-3 ; 2.03 \\
(0.77)\end{array}$ & 2.39 & 0.02 \\
\hline \multicolumn{6}{|c|}{$\begin{array}{l}\text { Fraboni Scale } \\
\text { Discrimination and negative emotional attitudes }\end{array}$} \\
\hline №16 & Most elderly people should not be trusted to take care of infants & $\begin{array}{l}2.0 ; 1-4 ; 2.10 \\
(0.82)\end{array}$ & $\begin{array}{l}3.0 ; 2-4 ; 3.09 \\
(0.72)\end{array}$ & -4.01 & 0.001 \\
\hline
\end{tabular}




\begin{tabular}{|c|c|c|c|c|c|}
\hline \multirow[t]{2}{*}{$\begin{array}{l}\text { Criterion } \\
\text { number }\end{array}$} & \multirow[t]{2}{*}{ Approvals } & \multicolumn{2}{|c|}{$\begin{array}{l}\text { Group (Median; min-max; } \\
\text { Mean (SD)) }\end{array}$} & \multicolumn{2}{|c|}{ Mann-Whitney U-test } \\
\hline & & 1 & II & $z$ & $p$ \\
\hline № 17 & $\begin{array}{l}\text { It is best that elderly people live where they won't bother } \\
\text { anyone }\end{array}$ & $\begin{array}{l}3.0 ; 1-4 ; 3.14 \\
(0.74)\end{array}$ & $\begin{array}{l}2.0 ; 1-4 ; 2.09 \\
(1.01)\end{array}$ & 3.72 & 0.001 \\
\hline \multicolumn{6}{|c|}{$\begin{array}{l}\text { Fraboni Scale } \\
\text { Alienation, avoidance }\end{array}$} \\
\hline № 6 & $\begin{array}{l}\text { I sometimes avoid eye contact with elderly people when I see } \\
\text { them }\end{array}$ & $\begin{array}{l}2.0 ; 1-4 ; 1.59 \\
(0.68)\end{array}$ & $\begin{array}{l}2.0 ; 1-4 ; 2.52 \\
(0,83)\end{array}$ & -4.05 & 0.001 \\
\hline № 13 & $\begin{array}{l}\text { I personally would not want to spend much time with an elderly } \\
\text { person }\end{array}$ & $\begin{array}{l}2.0 ; 1-4 ; 2.24 \\
(0.79)\end{array}$ & $\begin{array}{l}3.0 ; 2-4 ; 2.79 \\
(0.74)\end{array}$ & -2.45 & 0.01 \\
\hline №22 & I would prefer not to live with an elderly person. & \begin{tabular}{|l|}
$2.0 ; 1-4 ; 2.45$ \\
$(0.83)$ \\
\end{tabular} & $\begin{array}{l}2,0 ; 1-3 ; 2.0 \\
(0.83)\end{array}$ & 1.78 & 0.07 \\
\hline №10 & $\begin{array}{l}\text { Elderly people should feel welcome at the social gatherings of } \\
\text { young people }\end{array}$ & $\begin{array}{l}2.0 ; 1-4 ; 2.28 \\
(1.07)\end{array}$ & $\begin{array}{l}2.0 ; 1-3 ; 1.79 \\
(0.65)\end{array}$ & 1.71 & 0.09 \\
\hline \multicolumn{6}{|c|}{$\begin{array}{l}\text { UCLA Scale } \\
\text { Indicators of loneliness experience }\end{array}$} \\
\hline №1 & I feel good with the people around me & $\begin{array}{l}4.0 ; 2-4 ; 3.83 \\
(0.47) \\
\end{array}$ & $\begin{array}{l}4.0 ; 2-4 ; 3.42 \\
(0.66)\end{array}$ & 2.31 & 0.02 \\
\hline № 6 & I have a lot in common with the people around me & $\begin{array}{l}4.0 ; 2-4 ; 3.62 \\
(0.68)\end{array}$ & $\begin{array}{l}3.0 ; 1-4 ; 2.97 \\
(0.81)\end{array}$ & 3.06 & 0.001 \\
\hline № 9 & I am an outgoing person & $\begin{array}{l}4.0 ; 2-4 ; 3.69 \\
(0.60)\end{array}$ & $\begin{array}{l}3.0 ; 1-4 ; 3.03 \\
(0.92)\end{array}$ & 2.73 & 0.01 \\
\hline
\end{tabular}

The selected main component of the exploratory factor analysis determines the separation of the two groups of elderly adults. According to the semantic component of the statements of the scales of both questionnaires that "load" the main component, the most appropriate manifestation of the differentiating factor is polarization on the conditionally selected scale "extraversion-introversion". In the area of the extreme pole of the "extraversion" scale, the indicators of elderly people from the nursing home are predominantly clustered. In the area of the opposite pole ("introversion"), the peers from households were largely clustered.

\section{Discussion}

\section{Key results}

The present study identified factors that contribute to the occurrence of psycho-emotional disorders among elderly people from nursing homes and households. For group I, these are the objective factors of experiencing loneliness (constant stay in a permanent facility). For group II, these were subjective factors (associated with a lack of motivation for active life, negative social stereotypes or low self-esteem, most often due to the fear of being criticized, failing in a relationship or becoming psychological dependent). The results of the most pronounced factors for each of the studied groups of elderly people were confirmed statistically $(p<0.05)$.

\section{Interpretation}

Elderly people living in nursing homes and in households demonstrate the specificity of the severity of the characteristics and features of the subjective perception of the phenomenon of ageism and loneliness.

Subjectively experienced ageism and loneliness in the responses of elderly people from nursing homes and households

In general, in both groups of respondents, the total ageism index can be described as neutral or close to positive (about $80 \%)$. Therefore, it is reasonable to assume that the severity of ageism will decrease with the transformation of society and the associated fact of increasing satisfaction with life. A low range of the respondents' experience of loneliness was not established. Informants with medium and, especially, high levels of ageism, as expected, were significantly less likely to recognize the social significance of themselves and their peers in society. The revealed manifestations of ageism and feelings of loneliness coincide with the results presented in literature [8, 21-23].

Exploratory factor analysis using principal component analysis and the results of basic statistics

The conducted exploratory factor analysis showed that the entire set of correlations of respondents' indicators in the data set of the primary scales of both questionnaires was reduced to only three mutually independent factors, and only one of them described the division into groups. The greatest contribution to the factor describing the division into groups (the coefficients were standardized by normalization - bringing the standard deviation to 1) is shown by the following components of the Fraboni and UCLA questionnaires, according to the ranking by the absolute value of the contribution.

Elderly people living in nursing homes differ both in some of the statements in the Fraboni scale and in the statements specific to the experience of loneliness (UCLA):

- "Elderly people should feel welcome at the social gatherings of young people";

- "Many elderly people are stingy and hoard their money and possessions";

- "I am a contact and sociable person";

- "I have a lot in common with the people around me";

- "I have no one to whom I could (la) turn".

The results indicate that this group of respondents has a fairly positive image of an elderly person who has something to share with others and is open to communication.

The indicator of loneliness experience in the studied groups of elderly people is at an average level. The proportion of respondents with a high level of loneliness is greatest in the $1^{\text {st }}$ group.

For those living in households, the statements of the Fraboni scale are typical in descending order: №17 "It is best that elderly people live where they won't bother anyone" (with a negative contribution of 0.35 ); № 6 "I sometimes avoid eye contact with elderly people when I see them" (with a negative contribution of 0.32); №16 "Most elderly people should not be trusted to 
take care of infants" (with a negative contribution of 0.30); № 1 "Teenage suicide is more tragic than suicide among the elderly" (with a negative contribution of 0.27)"; №22 "I would prefer not to live with an elderly person" (with a negative contribution equal to 0.23); and № 24 "Elderly people complain more than other people do" (with a positive contribution equal to 0.21 ). This may indicate that this group of respondents has a negative image of an elderly person who looks unreliable and socially neglected. In this group, there are a number of psychological factors that contribute to loneliness. Avoiding contact with other people, most often because of the fear of being criticized, failing in a relationship or becoming psychologically dependent, which in turn leads to a drop in self-esteem and, as a result, alienation. People with poorly developed interpersonal skills also often tend to be lonely, especially if they already have bad experiences with other people. The experience of loneliness and its relationship with the reduction in the frequency of social communication can be considered as a reaction to the accelerated discriminatory stereotypes and other manifestations of ageism in society. The data is consistent with literature [24-26].

\section{Generalizability}

In this study, when studying the experience of ageism and loneliness, the most pronounced factors contributing to the occurrence of psycho-emotional disorders were identified. Special attention was paid to elderly people living in a nursing home due to the phenomenon of private institutions of the social service structure. Specific objective criteria indicating high levels of their experience of loneliness were identified. In this context, $31 \%$ of the elderly in group I and $15 \%$ of those in group II are most likely to develop psycho-emotional disorders.

\section{Limitations of the study}

The participants agreed to participate and presented with vital energy, activity and an unwillingness to give in to age, which may limit generalizability. Our research was conducted not only in Russia but also in Poland, Belarus and Lithuania.
This will allow us to analyze the phenomenon of ageism and loneliness in the subjective perception of elderly people living in nursing home and households. A limitation was the low samples size, limiting statistical power. Another limitation was lack of control for confounding. There may be other characteristics that are responsible for the results found.

\section{Conclusions}

The present study examined and evaluated subjectively experienced ageism and loneliness in elderly people living in nursing home and households. Practical recommendations can be extended to clients of the nursing home rehabilitation unit.

1. Manifestations of ageism and loneliness were identified among the elderly in both groups, and each group had their own characteristics.

2. For respondents from a nursing home, the frequency of occurrence of a high level of loneliness was twice as high as for peers from households. This was facilitated by the phenomenon of the closed structure of nursing homes as institutions of the domestic structure of social services.

3. For those living in households, the experience of loneliness was more typical in connection with the manifestations of ageism in the form of gerontostereotypization, discrimination and, especially, alienation-avoidance.

4. The high level of loneliness and ageism among the elderly should be considered as factors contributing to the emergence of psycho-emotional disorders.

Acknowledgments. The authors are grateful to all the patients who participated in the surveys.

Source of funding: This study and paper were supported by project of the Belarusian Republican Foundation for Fundamental Research and Russian Foundation for Basic Research (RFBR N 20-513-00002 Bel_a BRFFR-RFBR M20P-006).

Conflicts of interest: The authors declare no conflicts of interest.

\section{References}

1. Levy BR, Slade MD, Chang ES, et al. Ageism amplifies cost and prevalence of health conditions. Gerontologist 2020; 60(1): 174-181, doi: 10.1093/geront/gny131.

2. Ayalon L, Tesch-Römer C. Contemporary perspectives on ageism. International Perspectives on Aging, 19. Cham: Spring Open; 2018.

3. Wysokiński M, Fidecki W, Plech T, et al. Perception of old age by the inhabitants of Poland. Int J Environ Res Public Health 2020; 17(7): 2389, doi: 10.3390/ijerph17072389.

4. Kechyna EA, Filinskaya LV. [The quality of life of the older generation in Belarus]. RUDN Journal of Sociology 2020; 20(1): 30-49, doi: 10.22363/2313-2272-2020-20-1-30-49 (in Russian).

5. Manakova EA. [Experience of loneliness questionnaire]. Siberian Journal of Psychology 2018; 69:149-171, doi: 10.17223/17267080/69/9 (in Russian).

6. Cybulski M, Cybulski L, Krajewska-Kulak E, et al. The level of emotion control, anxiety, and self-efficacy in the older in Bialystok, Poland. Clin Interv Aging 2017; 12: 305-314, doi: 10.2147/CIA.S128717.

7. Klimatckaia LG, Shpakou Al, Zaitseva OI, et al. [Validity support for actions on minimization of gerontological ageism according to the recommendations of the world health organization]. Siberian Journal of Life Sciences and Agriculture 2020; 12(3): 94-107, doi: 10.12731/2658-6649-2020-12-3-94-107. (in Russian).

8. Buslaeva Ye. [Problem of subjective feeling of loneliness at advanced age]. Bulletin of Science and Practice 2016; 4: $510-515$ (in Russian).

9. Butler RN. Ageism: a foreword. J Soc Issues 1980; 36(2): 8-11, doi: 10.1111/j.1540-4560.1980.tb02018.x.

10. Marques S, Mariano J, Mendonça J, et al. Determinants of ageism against older adults: a systematic review. Int J Environ Res Public Health 2020; 17(7): 2560, doi: 10.3390/ijerph17072560.

11. Tomaszewska-Hołub B. [Stereotyping of old age - selected manifestations of ageism]. Cywilizacja i Polityka 2019; 17(17): 90-101 (in Polish).

12. Mikulionienè S, Jurkevits A, Rapolienè G. [Need for communication and the role of ageist attitudes in its fulfilment: a qualitative study of older people]. Adv Gerontol 2019; 32(1-2): 273-281 (in Russian).

13. Fried L, Prohaska T, Burholt V, et al. A unified approach to loneliness. Lancet 2020; 395(10218): 114, doi: 10.1016/S0140-6736(19)32533-4.

14. Cacioppo JT, Patrick W. Loneliness: Human nature and the need for social connection. New York: WW Norton \& Company; 2008.

15. Rychtaříková J. Perception of population ageing and age discrimination across EU countries. Population and Economics 2019; 3(4): 1-29, doi: 10.3897/popecon.3.e49760.

16. Fraboni M, Saltstone R, Hughes S. The Fraboni Scale of Ageism (FSA): an attempt at a more precise measure of ageism. Can J Aging 1990; 9: 56-66. 
17. Makarova EY. [Ageism and psychological preparation of students]. In: Gulyaev GY, eds. [Best research article 2016]. Penza: Science and Education; 2017: 335-339 (in Russian).

18. Russell D. UCLA Loneliness Scale (Version 3): Reliability, validity, and factor structure. J Pers Assess 1996; 66(1): 20-40, doi: 10.1207/ s15327752jpa6601_2.

19. Ishmukhametov IN. Psychometric characteristics of the UCLA loneliness scale (version 3): a study of university students. Computer Modelling and New Technologies 2006; 10(3): 89-95.

20. Fabrigar LR, Wegener DT, MacCallum RC, et al. Evaluating the use of exploratory factor analysis in psychological research. Psychological Methods 1999; 4(3): 272-299, doi: 10.1037/1082-989X.4.3.272.

21. Prohaska T, Burholt V, Burns A, et al. Consensus statement: loneliness in older adults, the 21st century social determinant of health? BMJ Open 2020; 10(8): e034967, doi: 10.1136/bmjopen-2019-034967.

22. Vauclair C-M, Marques S, Lima ML, et al. Subjective social status of older people across countries: the role of modernization and employment. J Gerontol Ser B Psychol Sci Soc Sci 2015; 70: 650-660, doi: https://doi.org/10.1093/geronb/gbu074.

23. Singh-Manoux A, Adler NE, Marmot MG. Subjective social status: its determinants and its association with measures of ill-health in the Whitehall II study. Soc Sci Med 2003; 56(6): 1321-1333, doi: 10.1016/s0277-9536(02)00131-4.

24. Kuhlmann BG, Kornadt AE, Bayen UJ, et al. Multidimensionality of younger and older adults' age stereotypes: the interaction of life domain and adjective dimension. J Gerontol Ser B Psychol Sci Soc Sci 2017; 72: 436-440, doi: 10.1093/geronb/gbv049.

25. Świderska M. [Ageism as a social problem]. Pedagogika Rodziny Family Pedagogy 2015; 5(4): 41-50 (in Polish).

26. Shpakou A, Klimatckaia L, Kuzniatsou A, et al. Medical care and manifestations of ageism in healthcare institutions: opinion of older people. The example of four countries. Fam Med Prim Care Rev 2021; 23(1): 69-74, doi: https://doi.org/10.5114/fmpcr.2021.103159.

Tables: 3

Figures: 0

References: 26

Received: 29.04 .2021

Reviewed: 13.05 .2021

Accepted: 06.07.2021

Address for correspondence:

Andrei Shpakou, MD, PhD, Assoc. Prof.

Department of Theory of Physical Culture and Sports Medicine

Yanka Kupala State University of Grodno

st. Ozheshko 22

230023 Grodno

Belarus

Tel.: +375 297831034

E-mail: shpakofff@tut.by 